\title{
Construção de arrays de tecido com equipamento alternativo e de baixo custo para estudo imuno-histoquímico de tumores mamários
}

\author{
Construction of low cost tissue microarrays using alternative equipment \\ for immunohistochemical study of breast tumors
}

Rafael Malagoli Rocha'; Victor Piana Andrade ${ }^{2}$; Cristiana Buzelin Nunes ${ }^{3}$; Gislene Fátima Silva Rocha4; Fernanda Squárcio Fernandes Sanches ${ }^{5}$; Flávio Nepomuceno Oliveira ${ }^{6}$; Helenice Gobbi ${ }^{7}$.

\begin{abstract}
unitermos
Array de tecidos

Câncer de mama

Imuno-histoquímica

Marcadores prognósticos

\section{resumo}

Introdução: Tissue microarrays (TMA) são blocos contendo numerosos cilindros de tecido parafinado organizados em linhas e colunas que permitem analisar muitas amostras numa única lâmina. Equipamentos disponíveis comercialmente são importados e têm alto custo (entre 11 e 24 mil dólares). Objetivos: Descrever uma forma alternativa de construção de arrays de tumores mamários de baixo custo e relatar nossa experiência na sua utilização em estudo imuno-histoquímico (IIQ). Metodologia: Utilizou-se modelo que consiste numa minirretífica com agulha de biópsia hepática de $2 \mathrm{~mm}$ de diâmetro acoplada à bancada com suporte (Dremel). Inicialmente preparou-se o bloco receptor fazendo o número de furos desejável (55). Cilindros de tecido foram obtidos com o mesmo dispositivo e colocados nos orifícios do bloco receptor. De cada bloco doador, obteve-se dois cilindros de diferentes áreas representativas do tumor. Em cada array foram incluídos cilindros de tumor (controle positivo e negativo) para cada anticorpo testado na IIQ, e cilindro marcador de iniciação da leitura da lâmina (fígado). Cortes seqüenciais de $4 \mu \mathrm{m}$ obtidos do array foram submetidos à IIQ. A primeira e a última lâmina foram coradas pela hematoxilina e eosina (HE) para avaliar: número de discos de tecido, preservação tecidual e adequabilidade da amostra. Foi realizada IIQ empregando anticorpos anti-receptores de estrógeno, progesterona, Ki67, p53 e Her2. Resultados: $\mathrm{O}$ custo total do equipamento foi apenas US $\$ 180,00$. Cortes histológicos do array apresentaram boa preservação tecidual, sendo adequados para avaliação morfológica e suficientes para confirmação diagnóstica. A qualidade das reações IIQ foi semelhante à obtida nos blocos doadores. Conclusão: Esse equipamento e a técnica representam uma alternativa econômica aos equipamentos comerciais.
\end{abstract}

abstract

Background: Tissue microarrays (TMA) are blocks containing numerous cylinders of paraffinized tissue organized in lines and columns allowing analysis of numerous samples in one slide. Commercially available equipment is imported and have high cost (US\$ 11,000.00 to 24,000.00). Aim: we describe a low cost breast-tumor TMA and our experience in its use for immunohistochemistry (IHC). Material and methods: A model that consists of a work station (Dremel) to which a liver biopsy needle of $2 \mathrm{~mm}$ of diameter was connected. A receptor block was prepared perforating it until the desired number of rows (55) was reached. Then, the cylinders of tissue were obtained using the same equipment and included in the holes of the receptor block. Two samples were obtained from different tumor areas of each donor block. Cylinders of previously tested positive control tumors for each antibody and one marker (liver sample) that indicated the beginning of slide reading were also included. IHC was performed in sequential $4 \mu \mathrm{m}$ sections from the same array using antibodies against estrogen and progesterone receptors, Ki67, p53 and Her2. The first and the last slides were stained by hematoxylin and eosin to evaluate: number of tissue discs, tissue preservation, and adequacy of the tissue sample. Results: The equipment total cost was US\$ 180,00. The slides showed fine tissue preservation, adequate for morphologic evaluation, and sufficient to confirm diagnosis. The IHC quality was similar to the donor blocks. Conclusion: This equipment and technique represent an economical alternative when compared to commercial equipments. key words

Tissue microarrays

Breast cancer

Immunohistochemistry

Prognostic markers

\footnotetext{
1. Mestrando do Programa de Pós-graduação em Patologia da Universidade Federal de Minas Cerais (UFMG).

2. Mestre em Patologia pela UFMG; doutorando do Programa de Pós-graduação em Ciências do Hospital do Câncer de São Paulo; assessor-médico do Instituto Fleury e do Hospital do Câncer de São Paulo.

3. Mestranda do Programa de Pós-graduação em Patologia da UFMG.

4. Bolsista de iniciação científica do Conselho Nacional de Desenvolvimento Científico e Tecnológico (CNPq).

5. Bolsista de iniciação científica da Fundação de Amparo à Pesquisa do Estado de Minas Cerais (FAPEMIC).

6. Bolsista de apoio técnico do CNPq

7. Professora-adjunta; doutora do Departamento de Anatomia Patológica da Faculdade de Medicina da UFMG.

Trabalho realizado no Laboratório de Patologia Mamária da Faculdade de Medicina da UFMG.

Trabalho realizado com apoio financeiro da FAPEMIG e do CNPq.

Resultados parciais do trabalho foram apresentados no XXV Congresso Brasileiro de Patologia, em Natal-RN, em outubro de 2005. Resumo publicado no / Bras Patol Med Lab, v. 41, n. 1, p. 51.0

trabalho recebeu o prêmio Osvaldo Ciannotti Filho, oferecido pela Escola Paulista de Medicina (EPM) ao melhor trabalho em Patologia Mamária apresentado no congresso.
} 


\section{Introdução}

Por mais de um século o material de estudo tem sido preservado em formalina e embebido em parafina, para que se realize microtomia e posterior análise. Esse método se tornou padrão para análises histopatológicas ${ }^{(13)}$. Em 1998, pesquisadores criaram um mecanismo para examinar várias amostras de tecidos diferentes de uma só vez, ao organizá-los num mesmo bloco de parafina utilizando pequenos cilindros de tecido(7). Esses arrays de tecidos foram referidos como tissue microarrays (TMA). Para a sua construção é usado um aparelho em que se utiliza uma agulha para retirar cilindros de tecidos incluídos em blocos de parafina preexistentes (bloco doador) e, posteriormente, são rearranjados em um novo bloco (bloco receptor). Dessa maneira, dezenas, e até centenas, de cilindros de tecidos podem ser colocados num único bloco de parafina. As lâminas obtidas pela microtomia desse bloco podem ser analisadas pela técnica rotineira de coloração por hematoxilina e eosina (HE) e/ou por várias outras técnicas, incluindo a IIQ, hibridização in situ fluorescente (FISH) e hibridização in situ cromogênica (CISH) ${ }^{(1,6,7,9-12)}$.

Para a construção do TMA convencional, o pesquisador estuda as lâminas originais e seleciona as áreas de interesse para o estudo. A seguir as áreas selecionadas são identificadas nos blocos de parafina arquivados (bloco doador) e um cilindro de tecido (que pode variar de $0,6 \mathrm{~mm}$ a $2 \mathrm{~mm}$ de diâmetro) é retirado dessa área com uma agulha acoplada a um equipamento de precisão disponível comercialmente. Esse cilindro é então introduzido em um novo bloco (bloco receptor). Os cilindros dos vários casos são sucessivamente adicionados ao bloco receptor e a posição de cada caso é identificada em uma planilha, com referências da coluna e da linha. Ao final, obtém-se um bloco receptor que pode conter até 1.000 amostras diferentes.

Apesar de a utilização do TMA estar amplamente validada pela literatura e seu uso ser cada dia mais difundido, ainda há poucos modelos de equipamentos (manuais ou automáticos) disponíveis comercialmente, entretanto os preços dos que estão no mercado variam entre 11 e 24 mil dólares (www.beecherinstruments.com).

A potencialidade do emprego dos TMAs no estudo de marcadores prognósticos e preditivos em tumores mamários humanos nos motivaram a montar e testar um equipamento alternativo, de baixo custo, para construir arrays de carcinomas de mama e, assim, validar sua aplicação na avaliação de diferentes anticorpos. O objetivo deste trabalho foi divulgar o nosso modelo alternativo para a construção de arrays de tecidos, bem como os resultados de seu emprego, para testar os marcadores moleculares mais utilizados em carcinoma de mama empregando imunoistoquímica.

\section{Material e método}

Foram selecionados 26 casos de carcinomas mamários invasivos (CMI) nos arquivos do Laboratório de Patologia Mamária do Departamento de Anatomia Patológica da Faculdade de Medicina da Universidade Federal de Minas Gerais (FM/UFMG). As lâminas originais coradas pela HE foram revistas, selecionando-se os respectivos blocos que apresentavam áreas mais representativas e preservadas do tumor.

Para a construção do TMA utilizou-se um dispositivo idealizado por um dos autores (Andrade VP), que consiste numa minirretífica (motor giratório) acoplada a uma bancada fixa com alavanca (Dremel, Alemanha) (Figura 1A), a qual permite que a máquina suba e desça respeitando os limites estipulados pelo manipulador. À minirretífica foi encaixada uma agulha de biópsia hepática de $2 \mathrm{~mm}$ de diâmetro e 1,5cm de comprimento, cortada e lapidada, utilizando lixas componentes do próprio equipamento. $\mathrm{O}$ custo total do equipamento e acessórios no ano de realização do trabalho (2005) foi de $\mathrm{R} \$ 400,00$ (US\$ 174,00).

A construção do TMA tem início com a confecção do bloco receptor. Primeiramente, um mapa para orientar o conteúdo dos orifícios foi elaborado em editor de texto, impresso em papel e fixado sobre a parafina amolecida do bloco receptor. Esse mapa contém os pontos exatos onde a agulha giratória deve penetrar para a retirada do cilindro de parafina, resultando na formação de um orifício para receber o cilindro de tecido tumoral obtido do bloco doador. Para esse trabalho fez-se um bloco receptor, com 55 orifícios organizados em cinco linhas e 11 colunas, seguindo a orientação do mapa.

De cada uma das duas regiões marcadas em cada bloco de parafina doador foi retirado um cilindro de tecido, que então era encaixado seqüencialmente nos orifícios do bloco receptor. Para retirar esse cilindro, abaixava-se a alavanca do suporte, fazendo com que a agulha giratória descesse e perfurasse o tecido, e subisse novamente com o cilindro em seu interior. A profundidade da perfuração era controlada pela régua milimetrada da minirretífica e mantida constante para todos os cilindros. Em seguida, a agulha é retirada do suporte e, com o auxílio de um bastão internamente complementar ao diâmetro da agulha, o cilindro é retirado e encaixado no bloco receptor utilizando-se uma pinça (Figura 1B e 1C). 
No array foi incluído também um cilindro de fígado (primeiro cilindro colocado na linha 1/coluna 1), para orientar o início da leitura e o direcionamento das lâminas, e esse é referido como cilindro iniciador de leitura. Portanto, cada array continha 55 cilindros, sendo 52 representando 26 casos de tumores mamários em duplicata, dois de tumores previamente testados usados como controles positivos para os anticorpos a serem testados, e um cilindro de fragmento hepático como marcador do início de leitura da lâmina.

Cortes seriados foram obtidos de cada array até que o tecido de $30 \%$ dos cilindros não mais estivesse presente nas seções histológicas. As lâminas foram numeradas na ordem de retirada, obtendo-se até 70 lâminas de cada bloco. As lâminas que possuíam maior quantidade de discos de tecido preservados e melhor organização das linhas e colunas foram selecionadas para os testes de imunoistoquímica. Para determinar a representatividade do TMA em relação aos blocos doadores, selecionamos áreas no bloco correspondentes a campos visuais que contivessem no mínimo $20 \%$ de tumor à coloração por $\mathrm{HE}^{(8)}$.

Anticorpos monoclonais anti-receptores de estrógeno (RE) e progesterona (RP), Her2, p53 e Ki67 foram empregados, seguindo as recomendações dos fabricantes (Tabela). O método da estreptavidina-biotina-peroxidase (Biogenex, EUA) foi o empregado para o estudo IIQ. Os cortes histológicos foram submetidos à recuperação antigênica usando tampão citrato em calor úmido, para RE, RP, p53 e Ki67 e sem reativação antigênica para as lâminas coradas pelo Her2. Fez-se revelação das reações com diaminobenzidina e contracoloração com hematoxilina de Harris.

As lâminas foram analisadas semiquantitativamente, considerando-se positivas ou negativas segundo critérios da literatura ${ }^{(4)}$. A leitura das reações para RE, RP e p53 foi considerada positiva quando mais de $10 \%$ dos núcleos apresentavam coloração marrom, independentemente da intensidade da reação. O critério de Mello e Alves ${ }^{(9)}$ que

Tabela 1

\section{Anticorpos, clones, fabricantes e} diluição utilizados

\begin{tabular}{lccc}
\hline Anticorpo & Clone & Diluição & Fabricante \\
RE & 6F11 & $1: 100$ & Novocastra, UK \\
RP & PgR 312 & $1: 100$ & Novocastra, UK \\
Ki67 & MiB-1 & $1: 100$ & Dakocytomation, EUA \\
p53 & D07 & $1: 200$ & Dakocytomation, EUA \\
Her2 & CB11 & $1: 80$ & Novocastra, UK \\
\hline
\end{tabular}

RE: anti-receptores de estrógeno; RP: progesterona. considera a porcentagem de marcação dos núcleos tumorais foi utilizado para avaliação do Ki67 como índice proliferativo baixo (0\% a $10 \%)$, moderado (10\% a $25 \%$ ) e alto (acima de $25 \%$ ) de núcleos tumorais marcados. A leitura do Her2 foi realizada empregando os critérios propostos no Herceptest da Dakocytomation (www.dako.com). As colorações obtidas nas seções histológicas dos arrays foram comparadas às colorações originais realizadas em secções obtidas do bloco doador correspondente a cada cilindro, utilizando a mesma metodologia. A análise das colorações foi realizada por dois observadores (Rocha RM e Nunes CB) e as dúvidas e/ou discordâncias na leitura das reações foram revistas simultaneamente com um terceiro observador (Gobbi H) num microscópio de múltiplos observadores, chegando-se a uma leitura de consenso.

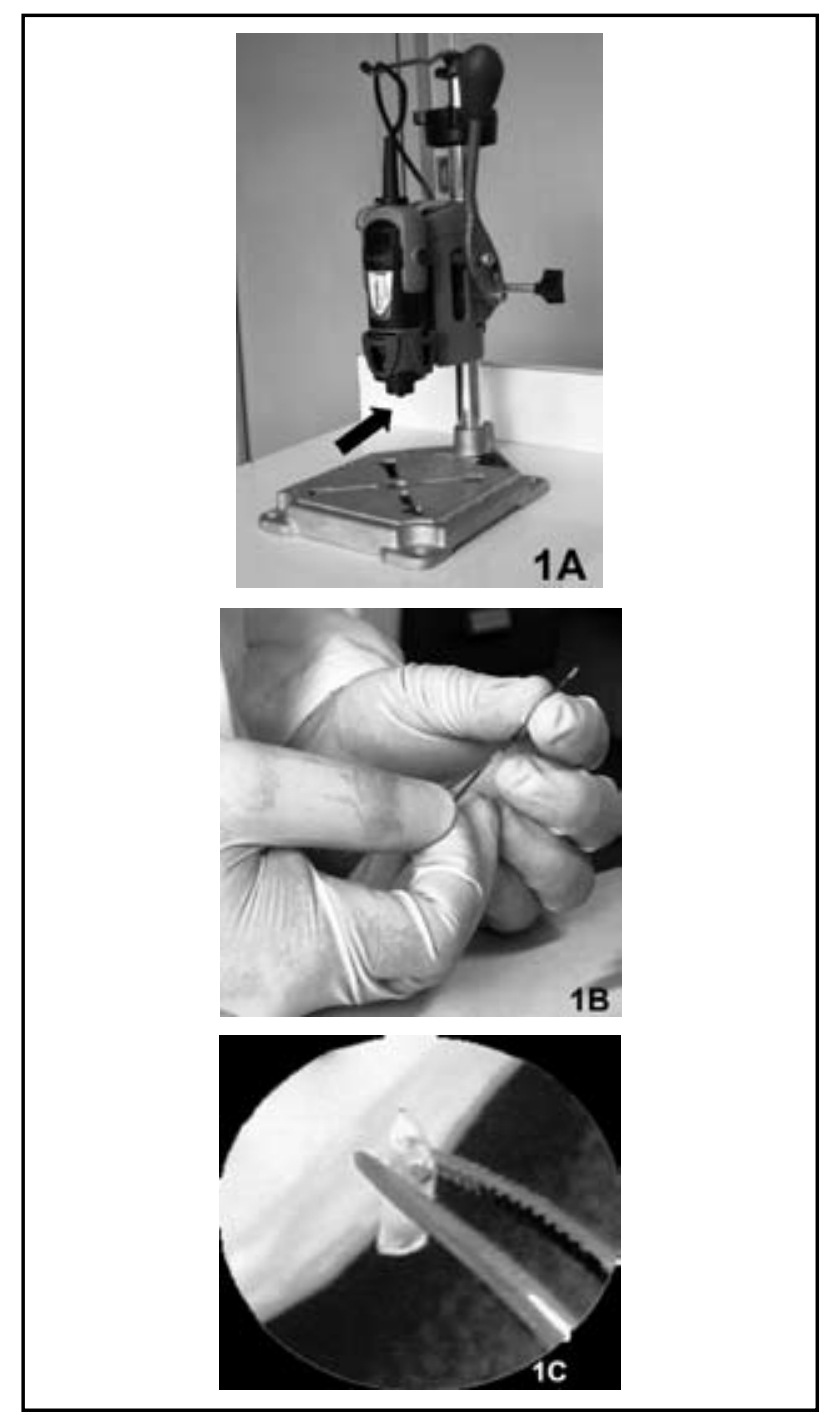

Figura 1 - Minirretífica acoplada a uma bancada fixa com alavanca (Dremel, Alemanha). Local de encaixe da agulha de biópsia hepática (seta) (1A). Retirada do cilindro de tecido parafinado do interior da agulha, que acaba de ser retirada do bloco doador, utilizando-se um bastão internamente complementar ao diâmetro da agulha (1B). Cilindro proveniente do bloco doador sendo conduzido com uma pinça ao seu orifício no bloco receptor (1C) 


\section{Resultados}

Após um período inicial de treinamento, em que foram construídos diferentes arrays, o tempo médio gasto para a construção do array descrito neste trabalho, com 55 cilindros de $2 \mathrm{~mm}$ de tecido, foi de 50 minutos (Figura 2A). Do bloco de TMA destinado a este trabalho foram obtidos 40 cortes histológicos seriados de $4 \mu \mathrm{m}$ de espessura, medindo 2,5 por $1,3 \mathrm{~cm}$. As lâminas inicial e final foram coradas pela HE. A análise macroscópica das lâminas para verificar a preservação dos cilindros de tecido revelou perda de um cilindro durante a microtomia, após o décimo primeiro corte. Como de cada caso foram incluídos dois cilindros de tecido, pôde-se analisar o outro cilindro do mesmo caso que estava presente em todas as lâminas, com amostra suficiente para o diagnóstico histopatológico. A qualidade da coloração avaliada nas colorações pela HE mostrou que todos os cilindros apresentaram boa preservação tecidual, que foi suficiente para a confirmação diagnóstica.

Na lâmina inicial faltaram 10 discos e na lâmina final faltaram sete. Para o estudo imunoistoquímico foram selecionadas 26 lâminas obtidas da porção média do array, entre as seções de números 8 e 34, que apresentavam discos de tecido mais preservados e com menor fragmentação. As reações IIQ obtidas nas lâminas dos arrays apresentaram qualidade semelhante às obtidas nos cortes histológicos integrais dos blocos doadores (Figura 2B).

Entre as lâminas submetidas à IIQ houve maior perda de discos de tecido naquelas submetidas à recuperação antigênica (RE, RP, p53 e Ki67). A maior perda foi de dez discos, na lâmina corada para p53 e a menor foi de dois discos na lâmina corada para RP.

Os resultados da análise IIQ dos diferentes anticorpos foram semelhantes nos discos de TMA e nas secções dos blocos originais de todos os casos, revelando representatividade acima de $95 \%$, com a utilização dos mesmos clones e método IIQ.

\section{Discussão}

Neste trabalho descrevemos um modelo alternativo de equipamento para construção de arrays de tecidos. Nosso equipamento custou cerca de US\$180,00 referentes ao valor da minirretífica, da bancada e dos acessórios. O custo dos equipamentos manuais comercialmente disponíveis pode variar entre 11 e 24 mil dólares. A esse valor deve ser acrescido US $\$ 200,00$ referentes ao custo das agulhas de $2 \mathrm{~mm}$, que são vendidas em jogos com 10 unidades (www. beecherinstruments.com).

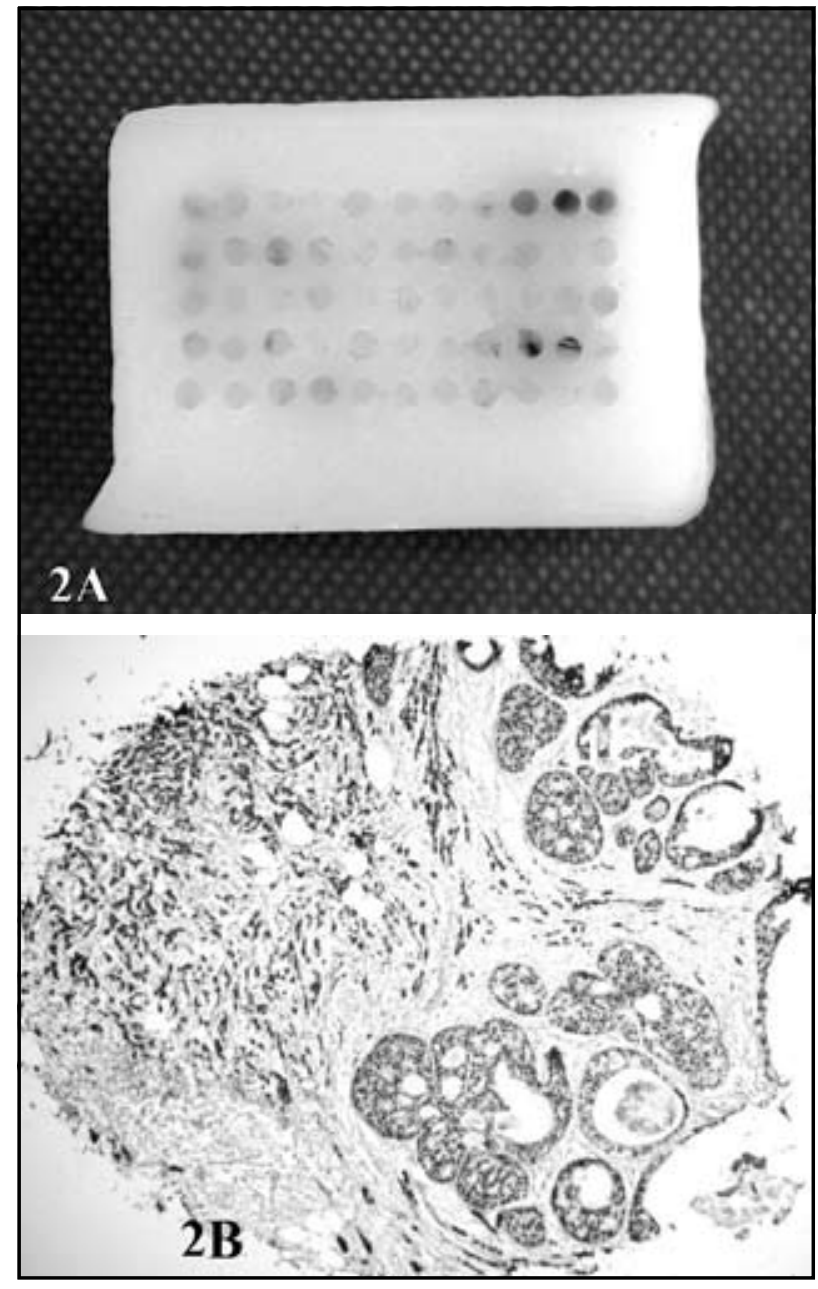

Figura 2 - Bloco receptor deste modelo artesanal de TMA completo com 55 cilindros (2A). Corte de um cilindro (um disco) em aumento de 10x corado pela IIQ com anticorpo anti RE, clone $6 F 11$ da Biogenex (2B)

O tempo gasto na construção do array foi relativamente curto (aproximadamente $50 \mathrm{~min}$ ). No entanto, o tempo despendido na análise das lâminas dos arrays foi maior, embora o trabalho de se analisar uma circunferência de tecido do TMA seja praticamente o mesmo empregado na análise do hot spot de um corte convencional. Para a análise dos 55 cilindros do array é necessário um esforço de concentração maior, para seguir a seqüência das linhas e colunas a partir do disco de iniciação de leitura da lâmina.

A microtomia do bloco de TMA também representou maior dificuldade do que cortar um bloco de parafina com um ou dois fragmentos de tecido. Ao se colocar a fatia de parafina com os cilindros de tecido no banho-maria histológico para se distender o material, o corte tendia a abrir, desorganizando as linhas e colunas. Esse problema, em geral, não ocorre ou é minimizado quando se usa a fita adesiva vendida como acessório dos equipamentos disponíveis comercialmente. A fita adesiva facilita manter 
a ordenação dos discos no TMA, evitando sua perda. Não encontramos na literatura dados numéricos referentes à perda dos discos de TMA construídos com arrays, disponíveis comercialmente, que pudessem ser comparados aos resultados de nossa técnica alternativa. Observamos também perda de discos de tecido durante a técnica de IIQ, mesmo utilizando lâminas silanizadas que aumentam a adesão do tecido à lâmina.

As bordas de nossos discos de tecido ficaram lisas e uniformes, pois as agulhas foram previamente bem lapidadas utilizando-se lixas que são adquiridas junto com o equipamento que utilizamos. Entre os acessórios disponíveis comercialmente estão jogos de agulhas descartáveis, de diferentes calibres, que são substituídas à medida que o gume fica gasto. O custo, no entanto, é bem maior que o nosso material alternativo, porquanto utilizamos agulhas de biópsia hepática reaproveitadas após seu uso clínico (www. beecherinstruments.com).

As informações sobre a representatividade do tecido da amostra no TMA, em relação ao tecido original, são variáveis e dependem do diâmetro do cilindro e de quantos cilindros são inseridos no TMA. Não há uma norma geral na literatura sobre quantos cilindros representam o tumor original.

Camp et al. ${ }^{(2)}$ construíram um array, utilizando equipamento convencional com 10 cilindros de tecido $(0,6 \mathrm{~mm}$ cada) de cada caso de neoplasia mamária invasora, sendo as áreas selecionadas quando, no mínimo, 10\% da circunferência era constituída pelo tumor. Esses autores observaram que, na análise dos receptores de estrógeno e do HER2 neu, em apenas um caso não houve concordância entre o array e o bloco original. Outro trabalho relata a construção de arrays com cinco cilindros de $0,6 \mathrm{~mm}$ de diâmetro representativos de cada caso $^{(5)}$.

O TMA artesanal que descrevemos apresentou representatividade tecidual acima de $95 \%$ em relação aos blocos doadores, tanto no resultado IIQ quanto no diagnóstico pela coloração HE. Assim, tendo utilizado dois cilindros com $2 \mathrm{~mm}$ de diâmetro, cada um representando um tumor, obtivemos áreas representativas tanto para confirmação diagnóstica pela $\mathrm{HE}$, quanto para avaliação IIQ, com resultados equivalentes aos obtidos dos blocos doadores. Semelhante ao nosso trabalho, outros autores obtiveram representatividade de até $95 \%$ com dois cilindros de 0,6 $\mathrm{mm}$, utilizando arrays comercialmente disponíveis ${ }^{(2)}$.

Portanto, concluindo, o equipamento e a técnica de construção do array descritos neste trabalho representam uma alternativa econômica aos equipamentos comerciais para construção de arrays de tecido, bem como permitem boa concordância diagnóstica com os cortes de blocos originais corados pela HE e no estudo IIQ de marcadores prognósticos em tumores mamários.

\section{Agradecimentos}

À Fundação de Amparo à Pesquisa de Minas Gerais (FAPEMIG), à Fundação Coordenação de Aperfeiçoamento de Pessoal de Nível Superior (CAPES) e ao Conselho Nacional de Desenvolvimento Científico e Tecnológico (CNPq).

\section{Referências}

I. BUBENDORF, L. et al. Hormone therapy failure in human prostate cancer: analysis by complementary DNA and tissue microarrays. J Natl Cancer Inst, v. 91, p. 1758-64, 1999.

2. CAMP, R.L. et al. Validation of tissue microarray technology in breast carcinoma. Lab Invest, v. 80, p. 1943-9, 2000.

3. FERREIRA, J.E.A. et al. Caracterização clínica e imunoistoquímica dos adenomas clinicamente não-funcionantes de hipófise. Arq Neuro Psiquiatr, v. 63, n. 4, 2005

4. FITZGIBBONS, P.L. et al. Prognostic factors in breast cancer. Arch Pathol Lab Med, v. I24, p. 966-78, 2000.

5. GULMANN, C. et al. Biopsy of a biopsy: validation of immunoprofiling in gastric cancer biopsy tissue microarrays. Histopathol, v. 42, p. 70-6, 2003.

6. HOOS,A.; CORDON-CARDO, C.Tissue microarray profiling of cancer specimens and cell lines: opportunities and limitations. Lab Invest, v. 81, p. |331-8, 2001.
7. KONONEN, J. et al. Tissue microarrays for high throughput molecular profiling of tumor specimens. Nature Med, v. 4 , p. 844-7, 1998.

8. LAYFIELD, L.J. et al.Tissue heterogeneity of immunohistochemically detected estrogen receptor: implications for image analysis quantification. Am J Clin Pathol, v. I I 0, p. 758-64, 1998.

9. MELLO, E.S.; ALVES, V.A.F. Determinação da fração de proliferação celular no carcinoma de mama pela marcação imunoistoquímica do antígeno nuclear Ki67: comparação dos métodos quantitativo e semiquantitativo. J Bras Patol, v. 35, p. 200-5, 1999.

10. $\mathrm{MOCH}, \mathrm{H}$. et al. Tissue microarrays: what will they bring to molecular and anatomic pathology? Adv Anat Pathol, v. 8, p. |4-20, 200|.

I I. MUCCl, N.R. et al. Neuroendocrine expression in metastatic prostate cancer: evaluation of high throughput tissue 
microarrays to detect heterogeneous protein expression. Hum Pathol, v. 31, p. 406-14, 2000.

12. PERRONE, E.E. et al.Tissue microarray assessment of prostate cancer tumor proliferation in African American and white men. J Nat Cancer Inst, v. 92, p. 937-9, 2000.

13. SCHRAML, P. et al. Tissue microarrays for gene amplification surveys in many different tumor types. Clin Cancer Res, v. 5, p. 1966-75, 1999.

14. WRIGHT JR, J.R. The development of the frozen section technique, the evolution of surgical biopsy, and the origins of surgical pathology. Bull Hist Med, v. 59, p. 295-326, 1985. 